\title{
IMPLEMENTASI STAD-PjBL UNTUK MENINGKATKAN KREATIVITAS PRODUK MAHASISWA CALON GURU BIOLOGI
}

\author{
Iin Hindun \& H. Husamah \\ FKIP Universitas Muhammadiyah Malang, Indonesia \\ Email: Iinhindunhindun@yahoo.co.id
}

\begin{abstract}
ABSTRAK
Kreativitas produk, khususnya dalam pengembangan perangkat pembelajaran, perlu dimiliki oleh calon guru biologi, dan hal tersebut masih rendah di Program Studi Pendidikan Biologi-Fakultas Keguruan dan Ilmu Pendidikan-Universitas Muhammadiyah Malang. Penelitian ini bertujuan untuk menganalisis peningkatan kreativitas produk pada mahasiswa melalui penerapan model STAD-PjBL. Jenis penelitian ini merupakan Penelitian Tindakan Kelas (PTK). Pendekatan dalam penelitian ini adalah kualitatif. Penelitian ini dilaksanakan dalam 3 siklus tindakan, setiap siklus terdiri atas dua kali pertemuan selama 2 jam pelajaran (2x50 menit). Setiap siklus tindakan terdiri atas empat tahapan yang mengacu pada Spiral Model, yaitu perencanaan, pembelajaran, pengamatan, dan refleksi. Sintaks pembelajaran yang diimplementasikan dalam pembelajaran adalah perpaduan STAD dan PjBL. PTK ini melibatkan 35 orang mahasiswa yang menempuh mata kuliah Perencanaan Pembelajaran Biologi. Instrumen penelitian berupa lembar penilaian kreativitas produk (terdiri atas 6 indikator, yaitu persiapan, proses perencanaan desain, isi desain rencana proyek, presentasi desain, presentasi produk, dan produk), yang diisi oleh tiga orang observer selama 3 siklus berlangsung. Hasil penelitian menunjukkan bahwa ada peningkatan rerata kreativitas produk sebanyak 18 point (Pra Siklus: 63; Siklus I: 71; Siklus II: 76; Siklus III: 81). Keenam komponen kreativitas produk mengalami peningkatan, baik itu persiapan, proses perencanaan desain, isi desain rencana proyek, presentasi desain, presentasi produk, dan produk. Dengan demikian dapat disimpulkan bahwa penerapan implementasi STAD-PjBL mampu meningkatkan kreativitas produk pada mahasiswa calon guru, meskipun masih pada level "baik".
\end{abstract}

Kata Kunci: Calon Guru Biologi; Kreativitas Produk; Perangkat Pembelajaran; STAD-PjBL

\section{ABSTRACT}

Product creativity, especially in developing learning tools, needs to be owned by prospective biology teachers. This element were still low in the Department of Biology Education-FTTE (Faculty of Teacher Training and Education) at the Universitas Muhammadiyah Malang. This research aimed to analyze the increase in product creativity in students through the application of STAD-PJBL. This research employs Classroom Action Research (CAR) in qualitative approach. This research was conducted in 3 action cycles, each cycle consisted of two meetings over 2 hours of learning ( $2 \times 50$ minutes). Each cycle of action carried out four stages that refer to the Spiral Model, namely planning, learning, observing, and reflecting. The learning syntax that is implemented in learning is a combination of STAD and PJBL. This class action research involved 35 students who took Biology Learning Planning courses. The research instrument was in the form of a product creativity assessment sheet (consisting of 6 indicators, namely preparation, design planning process, content of the project plan design, design presentation, product presentation, and product), which was conducted by 3 observers for 3 cycles. The results showed that the average increase in product creativity was 18 points (Pre-Cycle: 63; Cycle I: 71; Cycle II: 76; Cycle III: 81). The six components of product creativity have increased in preparation, design planning process, content of the project plan design, design presentation, product 
presentation, and product. It can be concluded that the implementation of STAD-PjBL implementation is able to increase product creativity in prospective teacher students, although it is still at the "good" level.

Keywords: Prospective Biology Teachers; Product Creativity; Learning Tools; STAD-PjBLL

\section{PENDAHULUAN}

Perkuliahan biologi dan pembelajarannya memiliki misi untuk mencetak mahasiswa terampil memecahkan masalah dan memiliki keterampilan berpikir kreatif yang menjadi modal untuk menciptakan karya nyata (Jumroh, 2016), atau disebut dengan kreativitas produk. Pengembangan kreativitas sangat bermanfaat bagi mahasiswa dalam beradaptasi dengan tuntutan kehidupan (Irmayati, 2017). Calon guru biologi diharapkan memiliki kreativitas membuat produk sehingga dapat mengajar dan membelajarkan dengan baik (Muspiroh, 2015), yang dalam hal ini terkait dengan merencanakan dan menyiapkan perangkat pembelajaran. Kreativitas mengandung arti bentuk berpikir untuk menghasilkan hal baru, tak terduga, dan bermanfaat. Kreativitas juga mencakup mengembangkan ide-ide baru, menemukan cara-cara baru dalam memecahkan persoalan, dan menghadapi peluang (Kurniasari, 2018).

Kreativitas lebih menekankan pada produk dan kinerja (performance) individu. Proses perkuliahan yang didesain sebagai upaya untuk mendapatkan pengetahuan melalui mekanisme membangun sendiri konsep dan berorientasi pada keterlibatan mahasiswa secara kreatif untuk menghasilkan produk akan membangkitkan motivasi mahasiswa (Gunawan, 2014). Produk yang dihasilkan mahasiswa menjadi gambaran yang autentik, nyata, dan dapat diukur oleh dosen (Muspiroh, 2015).

Salah satu mata kuliah yang wajib ditempuh mahasiswa di Program Studi Pendidikan Biologi-Fakultas Keguruan dan Ilmu Pendidikan-Universitas Muhammadiyah Malang adalah mata kuliah Perencanaan Pembelajaran Biologi. Mata kuliah ini bertujuan memberikan bekal kepada mahasiswa agar mereka dapat menganalisis materi pelajaran jenjang sekolah menengah atas (SMA), membuat program persiapan mengajar (perangkat pembelajaran berupa Rencana Pelaksanaan Pembelajaran atau RPP yang lengkap dengan lampiran), dan melakukan simulasi pembelajaran sesuai dengan panduan dan ketetapan pemerintah. Hal ini sejalan 
dengan Agustina, Yusron, dan Muyassarah (2018) bahwa mahasiswa calon guru Biologi harus memiliki bekal yang cukup terkait keterampilan-keterampilan yang berkaitan dengan tugas guru. Salah satu tugas utama guru adalah membuat persiapan mengajar dan melaksanakan pembelajaran yang diakhiri dengan evaluasi.

Peneliti sebagai tim dosen pengampu mata kuliah ini merasa bahwa perlu upaya pembenahan dan perbaikan dalam proses pembelajaran yang dilakukan. Hal ini sebagai upaya untuk terus memaksimalkan proses pembelajaran, menghindari kejenuhan dan kondisi monoton dalam pembelajaran, dan perlunya perbaikan dari sudut pandang mahasiswa. Berdasarkan refleksi terhadap situasi dan kondisi mahasiswa yang menempuh mata kuliah ini yang dilaksanakan pada awal Semester Ganjil tahun 2019-2020, didapatkan bahwa: 1) Mahasiswa perlu terus dikondisikan dalam sebuah pendekatan pembelajaran yang inovatif, yang menekankan belajar kontekstual, kooperatif, dan melalui kegiatan-kegiatan yang kompleks seperti membuat sesuatu yang akhirnya menghasilkan produk. 2) Mahasiswa perlu diberikan tugas yang menantang terkait dengan tugas profesinya kelak, mengembangkan dan melibatkan unsur keterampilan,. 3) Mahasiswa perlu diberi kesempatan untuk bekerja secara otonom untuk mengkonstruksi pengetahuan mereka sendiri dan mencapai puncaknya untuk menghasilkan produk nyata. 4) Banyak ditemui ketidakantusiasan mahasiswa dalam mengikuti proses pembelajaran. Banyak mahasiswa yang tidak memperhatikan penjelasan dosen pada saat proses pembelajaran berlangsung. 5) Mahasiswa lebih tertarik atau senang ketika kegiatan pembelajaran berupa diskusi. 6) Mahasiswa belum diminta untuk mengaitkan pengetahuan yang telah miliki dengan materi yang akan mereka pelajari atau menyadari apa yang telah mereka ketahui dari materi yang akan dipelajari. 7) Mahasiswa belum diminta untuk mengembangkan kemampuan berpikir, melakukan refleksi atas pembelajaran yang mereka lakukan, dan mengembangkan inisiatif.

Berdasarkan hasil diskusi dan kesepakatan bersama dengan tim pengampu mata kuliah dan para observer maka disepakati fokus penelitian, yaitu pengembangan kreativitas produk pada mahasiswa. Sebagai upaya mencapai target , pemenuhan tujuan mata kuliah, dan kajian literatur maka disepakati perlunya implementasi Project-based Learning (PjBL) yang dipadukan dengan model 
pembelajaran lain untuk memperoleh inovasi pembelajaran. PjBL merupakan salah satu model pembelajaran yang mendorong pengembangan aspek kemampuan berpikir, mengkomunikasikan gagasan, dan membuat karya/produk kreatif (Fitri, Dasna, \& Suharjo, 2018; Kurniawan, 2017; Luthfi, Ismail, \& Wiharto, 2013; Maula, Prihatin, \& Fikri, 2014; Sari \& Angreni, 2018). PjBL menekankan kegiatan belajar berdurasi lebih lama, holistik-interdisipliner, student-centered, dan terintegrasi dengan praktik serta isu-isu kontekstual, serta realistik (Muspiroh, 2015; Syam, 2016). PjBL berpotensi untuk mengembangkan problem-solving skills dan kreativitas produk (Jumroh, 2016).

PjBL memiliki 6 tahap, yaitu (1) menyusun pertanyaan mendasar (start with the essential question), (2) menyusun perencanaan proyek (design a plan for the project), (3) menyusun jadwal (create a schedule), (4) memonitor (monitor the students and the progress of the project), (5) menguji hasil (assess the outcome), dan 6) evaluasi pengalaman (evaluate the experience) (Kemendikbud, 2013). Kelemahan PjBL adalah terbatasnya tahap penjelasana dari guru/dosen (lecturing) dan tidak adanya tahap pemberian penghargaan (giving reward). Padahal tahap lecturing sangat penting bagi mahasiswa karena memberi bekal atau penguatan agar tidak salah konsep, ataupun menyelesaikan masalah yang mungkin mereka hadapi dalam proses pembelajaran. Tidak adanya tahap "pemberian penghargaan" memungkinkan tidak maksimalnya pengembangan motivasi dan percaya diri mahasiswa (Husamah \& Pantiwati, 2014). Selain itu, sebagai upaya memperkaya khasanah model pembelajaran yang dapat digunakan guru/dosen dalam mengajar, agar tidak terjadi kejenuhan, dan sebagai upaya pengembangan kualitas pembelajara, maka PjBL perlu dikembangkan, atau setidaknya diintegrasikan dengan model pembelajaran lain. Tim sepakat untuk memadukan PjBL dengan salah satu tipe dari model pembelajaran kooperatif, yaitu Student Team Achievement Division (STAD).

STAD dikembangkan oleh Robert E. Slavin pada tahun 1978. STAD adalah teknik kerja tim yang sederhana. Peserta didik dikumpulkan dalam satu kelompok yang terdiri atas empat atau lima anggota. Mereka kemudian mengambil kuis individu dan mengumpulkan poin untuk kelompok mereka. Skor masing-masing peserta didik dibandingkan dengan peserta didik lain dari kinerja terdahulu yang 
serupa, sehingga dalam STAD peserta didik dari berbagai level kemampuan memiliki peluang yang sama untuk mendapatkan poin maksimum. STAD dapat membangun hubungan yang kuat di antara peserta didik dan dapat membantu peserta didik untuk belajar bersama sebagai rekan satu kelompok. Selain itu, STAD mudah digunakan dan berlaku untuk semua tingkat usia atau kurikulum apa pun yang menuntut peserta didik untuk bekerja bersama dalam satu kelompok (Ghaith, 2001; Glomo-narzoles \& Ph, 2015; Khan \& Inamullah, 2011; Sherman, 2001; Tran, 2013; Warawudhi, 2012).

STAD dapat diterapkan untuk kelompok kemampuan campuran, yang melibatkan pengakuan dan tanggung jawab kelompok untuk pembelajaran individu. Efek positif dari STAD pada prestasi akademik telah terbukti dalam banyak penelitian. Penelitian mengungkapkan bahwa metode STAD membantu peserta didik untuk tampil lebih baik. Kesimpulan yang diperoleh adalah bahwa STAD mendorong peserta didik untuk berpartisipasi aktif dalam proses pembelajaran. Studi lebih lanjut tentang penggunaan STAD dilakukan menunjukkan bahwa penggunaan STAD secara signifikan meningkatkan kinerja akademik mahasiswa secara keseluruhan. Selain itu, peserta didik juga menunjukkan minat yang tinggi dalam belajar setelah diajarkan menggunakan metode STAD (Ghaith, 2001; Glomo-narzoles \& Ph, 2015; Khan \& Inamullah, 2011; Nair \& Kim, 2014; Sherman, 2001; Tran, 2013; Warawudhi, 2012).

Kooperatif STAD menekankan pada berbagai karakteristik pembelajaran langsung di mana peserta didik, dalam kelompok kecil, belajar dan berbagi informasi. Namun demikian, terdapat kelemahan pembelajaran kooperatif, termasuk dalam hal ini STAD, yaitu kadang-kadang membingungkan bagi peserta didik, dan kelompok yang dibuat oleh pendidik tidak seimbang (misalnya beberapa kelompok memiliki anggota yang terampil, dan kelompok lain memiliki anggota yang kurang terampil) karena teknik pengelompokan adalah melalui undian (Ghufron \& Ermawati, 2018). Oleh karena itu, sangat mungkin bila STAD dipadukan dengan PjBL, sebagaimana yang telah dilakukan oleh beberapa peneliti sebelumnya (Husamah \& Pantiwati, 2014; Masruroh, Ibrohim, \& Masjhudi, 2016; Suswanto et al., 2017; Zaturrahmi, Hamdi, \& Ratnawulan, 2017). 
Implementasi perpaduan STAD-PjBL masih sangat terbatas, khususnya untuk pembelajaran di perguruan tinggi, dan terlebih untuk bidang Biologi atau Pendidikan Biologi, Hasil penelusuran literatur menunjukkan bahwa hanya dua penelitian terkait STAD-PjBL. Hasil penelitian di jenjang SMA menunjukkan bahwa STAD dan PjBL berpengaruh secara signifikan terhadap penguasaan konsep, kemampuan memecahkan masalah, dan kemampuan berpikir kreatif siswa kelas XI. Peneliti menyarankan agar guru dapat menjadikan pembelajaran STAD dan PjBL sebagai alternatif penggunaan model dalam proses pembelajaran di kelas (Masruroh et al., 2016). Implementasi di program studi Pendidikan biologi menunjukkan bahwa STAD-PjBL mampu meningkatkan motivasi, kemampuan berpikir, dan hasil belajar mahasiswa (Husamah \& Pantiwati, 2014). Implementasi STAD-PjBL belum pernah dilakukan di mata kuliah Perencanaan Pembelajaran Biologi. Satu penelitian sebelumnya hanya dilakukan di jenjang SMA, yang tentunya memiliki subyek dan kondisi yang berbeda. Sementara penelitian lain memang dilakukan di perguruan tinggi bahkan di program studi yang sama, namun pada angkatan berbeda (terpaut empat tahun). Selain itu, implementasinya pun dilakukan pada mata kuliah keilmuan Biologi (Biologi murni) yang tentunya memiliki karakteristik materi yang berbeda. Berdasarkan hal tersebut penelitian ini mutlak diperlukan dan merupakan sebuah inovasi.

Inovasi dan adaptasi proses pembelajaran harus terus dilakukan. Usaha yang dapat dilakukan adalah dengan mengimplementasikan proses belajar mengajar yang mendorong peningkatan kreativitas mahasiswa (Yuliarma, 2010). Dosen dituntut untuk memiliki kemampuan dalam memilih model pembelajaran atau strategi yang cocok dengan materi, bahan ajar (Gunawan, 2014), serta ketercapaian kompetensi dan hasil belajar yang diharapkan. Sehubungan dengan itu, perlu kiranya upaya pengintegrasian (memadukan) STAD dengan PjBL dan melihat hasilnya dalam implementasi yang nyata. Artikel ini bertujuan untuk menganalisis peningkatan kreativitas produk pada mahasiswa melalui implementasi pembelajaran STAD-PjBL pada mata kuliah perencanaan pembelajaran biologi. 


\section{METODE}

Jenis penelitian ini merupakan Penelitian Tindakan Kelas (PTK). Pendekatan dalam penelitian ini adalah pendekatan kualitatif. Penelitian ini dilaksanakan dalam 3 siklus tindakan, setiap siklus terdiri atas dua kali pertemuan selama dua jam pelajaran (2x50 menit). Setiap siklus tindakan yang dilaksanakan terdiri atas empat tahapan yang mengacu pada Spiral Model dari Kemmis, McTaggart, dan Nixon (2014), yaitu perencanaan, pembelajaran, pengamatan, dan refleksi. Sintaks pembelajaran yang diimplementasikan dalam pembelajaran adalah perpaduan STAD dan PjBL yang dimodifikasi oleh Husamah dan Pantiwati (2014).

Peneliti bertindak sebagai pihak yang mengelola instrumen, merencanakan tindakan, melaksanakan tindakan, dan yang melaporkan hasil tindakan (hasil penelitian). Selama pelaksanaan penelitian, peneliti dibantu tiga orang observer yang membantu dalam pengumpulan data yang diperlukan di dalam kelas sekaligus sebagai pihak yang memberikan masukan pada tahap perencanaan dan refleksi.

PTK ini dilaksanakan di Program Studi Pendidikan Biologi-Fakultas Keguruan dan Ilmu Pendidikan-Universitas Muhammadiyah Malang, yaitu pada Kelas VA (angkatan 2017-2018), pada mata kuliah Perencanaan Pembelajaran Biologi. Jumlah mahasiswa di kelas ini sebanyak 35 orang. Waktu pelaksanaan penelitian dilaksanakan pada Semester Ganjil Tahun Ajaran 2019/2020. Instrumen penelitian berupa lembar penilaian keterampilan produk (Husamah, 2013; Husamah \& Pantiwati, 2014), yang diisi oleh tiga orang observer, dan selama tiga siklus.

Analisis data dalam penelitian ini meliputi kegiatan mengelola data mentah, menyajikan data, menarik kesimpulan, dan melakukan refleksi. Dalam penelitian ini data yang diperoleh berupa data kreativitas produk yanag terdiri atas persiapan, proses perencanaan desain, isi desain rencana proyek, presentasi desain, presentasi produk, dan produk. Untuk memudahkan penilaian kualitas pembelajaran maka dibuat persentase yang mengacu pada Arikunto (2001) dan Huda (2013) seperti pada Rumus 1. 
$\mathrm{P}=(\mathrm{E} / \mathrm{N}) \times 100 \%$

(1)

Keterangan

$\mathrm{P}=$ Persentase kualitas/ketercapaian

$\mathrm{E}=$ total skor yang diperoleh

$\mathrm{N}=$ skor maksimal

Skor yang diperoleh selanjutnya disesuaikan dengan Tabel 1 untuk menentukan kategori.

Tabel 1. Kategori persentase kualitas/ketercapaian pembelajaran

\begin{tabular}{cc}
\hline Persentase (\%) & Kategori \\
\hline $86-100$ & Sangat baik \\
$76-85$ & Baik \\
$60-75$ & Cukup \\
$0-59$ & Tidak baik \\
\hline
\end{tabular}

\section{HASIL DAN PEMBAHASAN}

Pengalaman positif dan adanya kreativitas produk yang diperoleh siswa melalui Pembelajaran STAD-PjBL diharapkan mengakar kuat sehingga menjadi keterampilan yang melekat kuat, bahkan menjadi kepribadian dan karakter positif generasi bangsa. Penanaman karakter yang diintegrasikan dalam pembelajaran dapat memberikan pengalaman bermakna bagi mahasiswa, karena mereka tidak hanya akan memahami, tetapi mengimplementasikan dalam kehidupan sehari-hari.

Data hasil pengamatan tentang skor kreativitas produk mahasiswa disajikan pada Tabel 2.

Tabel 2. Skor kreativitas produk mahasiswa pada matakuliah Perencanaan Pembelajaran Biologi

\begin{tabular}{clcccc}
\hline \multirow{2}{*}{ No. Aspek } & \multicolumn{1}{c}{ Skor Siklus } \\
\hline & \multicolumn{1}{c}{ Pra } & I & II & III \\
\hline \multirow{2}{*}{1} & $\begin{array}{l}\text { PERSIAPAN } \\
\text { Menyiapkan Sumber Bacaan (Silabus dan } \\
\text { Literatur Pendukung) }\end{array}$ & 63 & 71 & 78 & 80 \\
\hline & $\begin{array}{l}\text { PROSES PERENCANAAN DESAIN } \\
\text { a. Pembagian Tugas } \\
\text { b. Keseriusan/Totalitas dalam bekerja }\end{array}$ & 64 & 75 & 77 & 80 \\
$\quad \begin{array}{l}\text { ISI DESAIN RENCANA PROYEK } \\
\text { a. Kelengkapan Komponen }\end{array}$ & 62 & 70 & 77 & 81 \\
b. Sistematika Penulisan dan Kerapian & 65 & 68 & 77 & 79
\end{tabular}

JINoP (Jurnal Inovasi Pembelajaran),Volume 5, Nomor 2, November 2019, hal 139-154 


\begin{tabular}{|c|c|c|c|c|c|}
\hline \multirow{2}{*}{ No. } & \multirow{2}{*}{ Aspek } & \multicolumn{4}{|c|}{ Skor Siklus } \\
\hline & & Pra & I & II & III \\
\hline \multirow{5}{*}{4} & c. Gagasan Inovatif & 65 & 70 & 70 & 80 \\
\hline & $\begin{array}{l}\text { PRESENTASI DESAIN: } \\
\text { a. Performanse }\end{array}$ & 65 & 70 & 76 & 80 \\
\hline & $\begin{array}{l}\text { b. Penguasaan dan kemampuan } \\
\text { mempertahankan ide/gagasan }\end{array}$ & 61 & 73 & 75 & 82 \\
\hline & $\begin{array}{l}\text { c. Keterbukaan dalam diskusi dan menerima } \\
\text { masukan }\end{array}$ & 65 & 70 & 77 & 84 \\
\hline & $\begin{array}{l}\text { PRESENTASI PRODUK: } \\
\text { a. Performansi }\end{array}$ & 63 & 71 & 75 & 82 \\
\hline \multirow[t]{6}{*}{5} & $\begin{array}{l}\text { b. Penguasaan dan kemampuan } \\
\text { mempertahankan ide/gagasan }\end{array}$ & 62 & 70 & 73 & 81 \\
\hline & $\begin{array}{l}\text { c. Keterbukaan dalam diskusi dan menerima } \\
\text { masukan }\end{array}$ & 60 & 74 & 77 & 80 \\
\hline & $\begin{array}{l}\text { PRODUK } \\
\text { a. Kesesuaian dengan desain awal/tujuan }\end{array}$ & 61 & 70 & 75 & 83 \\
\hline & b. Bentuk fisik (kemenarikan/kerapian) & 63 & 70 & 76 & 81 \\
\hline & c. Kesesuaian dan Kegunaan (aplikatif) & 64 & 70 & 77 & 83 \\
\hline & $\begin{array}{l}\text { d. Inovasi dan kreasi (kebaruan dan dampak } \\
\text { bagi perubahan kondisi } \\
\text { lingkungan/pembelajaran/siswa) }\end{array}$ & 62 & 72 & 78 & 82 \\
\hline \multirow{4}{*}{6} & $\begin{array}{l}\text { e. Kemampuan menyeleksi dan } \\
\text { menggunakan bahan }\end{array}$ & 62 & 72 & 76 & 80 \\
\hline & $\begin{array}{l}\text { f. Kemampuan menyeleksi dan } \\
\text { menggunakan alat/media }\end{array}$ & 63 & 70 & 76 & 82 \\
\hline & $\begin{array}{l}\text { g. Kemampuan menyeleksi dan } \\
\text { menggunakan teknik }\end{array}$ & 64 & 72 & 78 & 81 \\
\hline & Rerata skor & 63 & 70 & 76 & 81 \\
\hline
\end{tabular}

Tabel 2 menunjukkan bahwa peningkatan rerata kreativitas produk sebanyak 18 point dari Prasiklus ke Siklus III. Capaian kreativitas produk pada Siklus I dan Siklus II termasuk kategori cukup dan Siklus Siklus III termasuk kategori baik. Temuan tersebut menunjukkan bahwa implementasi STAD-PjBL mendorong peningkatan kreativitas produk mahasiswa.

Adanya peningkatan sebanyak 18 point menunjukkan bahwa dosen sebagai perencana tindakan dan pelaksanakan tindakan mampu menerapkan STAD-PjBL sebaik mungkin. Sejak Siklus I aktivitas mahasiswa terus meningkat, mereka semakin berani untuk melakukan semua tahapan atau aspek kreativitas, serta berani berdiskudi dalam kelompok dan dengan dosen terkait dengan hal-hal yang kurang dipahami. Pada siklus-siklus berikutnya (Siklus II) para mahasiswa semakin percaya diri melaksanakan semua tahapan atau aspek. Kondisi yang kondusif yang diciptakan oleh dosen berdasarkan pengalaman siklus sebelumnya mendorong mahasiswa untuk menyelesaikan tugas dengan baik, bekerja sama dengan teman, dan berdiskusi secara konstruktif. 
Peningkatan point setiap siklus, terlebih pada Siklus III, menunjukkan perubahan yang positif dapat dimaknai sebagai meningkatnya pemahaman dan kepekaan mereka terhadap semua tahapan STAD-PjBL dan tahapan kreativitas produk dalam proses pembelajaran. Mahasiswa sudah mulai menguasai tahapan, merasa nyaman, merasa bekerja dalam satu tim sehingga rasa percaya diri terus berkembang, tumbuh sikap mau bekerja sama, dan tanggung jawab.

Apabila peserta didik memiliki sikap positif terhadap pembelajaran, maka motivasi belajar akan meningkat, begitu juga sebaliknya. Demikian juga dengan kebutuhan peserta didik, jika pelajaran dianggap bermakna dalam kehidupan peserta didik, maka motivasi belajar peserta didik akan meningkat, begitu pula sebaliknya (Purwanti \& Gafur, 2018).

Temuan penelitian tersebut sejalan beberapa penelitian sebelumnya bahwa pembelajaran yang didesain dengan menghadirkan problem dan menuntut mahasiswa untuk mencari solusi kreatif-inovatif mendorong mahasiswa peduli dan memiliki sensitivitas tinggi karena pembelajaran bertujuan memberikan kesadaran, kreativitas, sensitivitas, dan kepekaan (Darling-Hammond, Flook, Cook-Harvey, Barron, \& Osher, 2019; Rais \& Aryani, 2017; Taylor \& Parsons, 2011; Yuliarma, 2010). Mahasiswa terkondisikan untuk mengeksplorasi pengalaman-pengalaman, pengetahuan dan teori yang telah dikonsturksi sebelumnya menjadi suatu ide solutif dan nyata (berbentuk produk). Proses ini diawali dengam mencari makna dan pemahaman terhadap sesuatu, kemudian mempertimbangkan keputusan dan lalu memberi solusi terhadap suatu permasalahan (Luthfi et al., 2013).

Temuan-temuan tersebut menunjukkan bahwa integrasi STAD-PjBL mendorong peningkatan kualitas pembelajaran yang dilakukan oleh dosen model. PjBL mendorong peningkatan kualitas pembelajaran karena dimungkinkan mendukung teori bahwa pembelajaran yang diberikan harus meningkatkan aktivitas mahasiswa (student-centered) untuk menemukan dan memecahkan masalah, bekerja kooperatif, dan kreatif (Antika \& Nawawi, 2017; Fitri et al., 2018; Munawaroh, 2014; Yustina \& Suwondo, 2015).

Kooperatif STAD dan PjBL merupakan pendekatan pembelajaran inovatif, yang menekankan belajar kontekstual melalui kegiatan-kegiatan kompleks (Siswono, Hartono, Kohar, Karim, \& Lastiningsih, 2019; Smith, 2010; Susanti, 
Susilowibowo, \& Hardini, 2019; Trisdiono, 2014). Fokus pembelajaran terletak pada konsep-konsep dan prinsip-prinsip inti dari suatu disiplin studi, melibatkan pebelajar dalam investigasi pemecahan masalah dan kegiatan tugas-tugas bermakna yang lain, memberi kesempatan pebelajar bekerja secara otonom mengkonstruk pengetahuan mereka sendiri, dan mencapai puncaknya menghasilkan produk nyata. PjBL menggunakan proyek/kegiatan sebagai media. Mahasiswa melakukan eksplorasi, penilaian, interpretasi, sintesis, dan informasi untuk menghasilkan berbagai bentuk hasil belajar. PjBL menggunakan masalah sebagai langkah awal dalam mengumpulkan dan mengintegrasikan pengetahuan baru berdasarkan pengalaman dalam beraktifitas secara nyata. $\mathrm{PjBL}$ dirancang untuk digunakan pada permasalahan komplek yang diperlukan siswa dalam melakukan insvestigasi dan memahaminya.

\section{SIMPULAN}

Dari hasil penelitian dapat disimpulkan bahwa penerapan STAD-PjBL mampu meningkatkan kreativitas produk pada mahasiswa calon guru pada mata kuliah perencanaan pembelajaran biologi, meskipun secara umum masih pada level "baik". Berdasarkan hal tersebut, saran yang diberikan adalah bahwa pembelajaran ini harus terus diterapkan dan dikembangkan sehingga kualitas pembelajaran menjadi sangat baik, dan keterampilan produk mahasiswa berimplikasi pada kompetensi profesional dan pedagogik mereka. Perlu pula dilakukan penerapan STAD-PjBL atau modifikasi dan pengembangan lainnya dalam pembelajaran mata kuliah-mata kuliah lain ataupun materi lain sehingga memperkaya khasanah pembelajaran biologi.

\section{DAFTAR PUSTAKA}

Agustina, P., Yusron, F. N., \& Muyassarah, F. (2018). Pedagogical content knowledge (PCK) mahasiswa calon guru biologi FKIP UMS pada matakuliah microteaching tahun akademik 2015/2016. In The 7th University Research Colloqium 2018 (pp. 101-108). Surakarta, Central Java, Indonesia: STIKES PKU Muhammadiyah Surakarta.

Antika, R. N., \& Nawawi, S. (2017). The effect of project based learning model in 
seminar course to student's creative thinking skills. JPBI (Jurnal Pendidikan Biologi Indonesia), 3(1), 72-79. doi: https://doi.org/10.22219/jpbi.v3i1.3905 Arikunto, S. (2001). Prosedur penelitian (Suatu pendekatan praktek). Jakarta: PT. Rineka Cipta.

Darling-Hammond, L., Flook, L., Cook-Harvey, C., Barron, B., \& Osher, D. (2019). Implications for educational practice of the science of learning and development. Applied Developmental Science, 0(0), 1-44. doi: https://doi.org/10.1080/10888691.2018.1537791

Fitri, H., Dasna, I. W., \& Suharjo, S. (2018). Pengaruh model project based learning (PjBL) terhadap kemampuan berpikir tingkat tinggi ditinjau dari motivasi berprestasi siswa kelas IV Sekolah Dasar Hikmatul. BRILIANT: Jurnal Riset Dan Konseptual, 3(2), 201-212.

Ghaith, G. (2001). Learners' perceptions of their STAD cooperative experience. System, 29(2), 289-301. doi: https://doi.org/10.1016/S0346-251X(01)000161

Ghufron, M. A., \& Ermawati, S. (2018). The strengths and weaknesses of cooperative learning and problem-based learning in EFL writing class: Teachers and students' perspectives. International Journal of Instruction, 11(4), 657-672. doi: https://doi.org/10.12973/iji.2018.11441a

Glomo-narzoles, D. T., \& Ph, D. (2015). Student Team Achievement Division (STAD): Its effect on the academic performance of EFL learners. American Research Journal of English and Literature, 1(4), 1-7. doi: https://doi.org/10.21694/2378-9026.15013

Gunawan, A. (2014). Pengembangan model bahan ajar melalui pendekatan kreatif produktif pembelajaran geometri dan pengukuran berbasis karakter. $P G S D$ : Jurnal Ilmiah Pendidikan Guru Sekolah Dasar, 7(13), 185-193.

Huda, M. S. (2013). Pengembangan modul pembelajaran thermal radiation untuk menunjang perkuliahan perpindahan panas mahasiswa D3 Teknik Mesin FT UNESA. Jurnal Pendidikan Teknik Mesin, 2(1), 15-23.

Husamah, H. (2013). Penerapan cooperative learning STAD terintegrasi projectbased learning untuk meningkatkan motivasi, kemampuan berpikir, hasil belajar, dan kesadaran metakognitif dengan tugas menulis jurnal belajar pada 
matakuliah sumber belajar dan media pembelajaran. Malang: Pendidikan Biologi FKIP Universitas Muhammadiyah Malang.

Husamah, H., \& Pantiwati, Y. (2014). Cooperative learning STAD-PjB: Motivation, thinking skills, and learning outcomes of biology department students. International Journal of Education Learning and Development, 2(1), 77-94.

Irmayati, I. (2017). Pengembangan instrumen penilaian keterampilan kreatif dalam pembelajaran tematik terpadu dengan pendekatan project based learning. Bandar Lampung: Universitas Lampung.

Jumroh, S. (2016). Pengaruh project based learning terhadap keterampilan berfikir kreatif siswa kelas X pada materi pencemaran lingkungan di SMA Perintis 2 Bandar Lampung. Bandar Lampung: Fakultas Tarbiyah dan Keguruan UIN Raden Intan Lampung.

Kemendikbud. (2013). Model pembelajaran berbasis proyek (Project based learning). Jakarta-Indonesia: Kementerian Pendidikan dan Kebudayaan.

Kemmis, S., McTaggart, R., \& Nixon, R. (2014). The action reseacrh planner: Doing critical participatory action research. Singapore: Springer. Retrieved from http://www.springer.com/978-981-4560-66-5

Khan, G. N., \& Inamullah, H. M. (2011). Effect of student's team achievement division (STAD) on academic achievement of students. Asian Social Science, 7(12), 211-215. doi: https://doi.org/10.5539/ass.v7n12p211

Kurniasari, R. D. (2018). Pengaruh inovasi produk, kreativitas produk, dan kualitas produk terhadap keunggulan bersaing (Studi kasus pada produk kerajinan enceng gondok “AKAR”). Program Studi Manajemen - Jurusan Manajemen Fakultas Ekonomi Universitas Negeri Yogyakarta.

Kurniawan, D. T. (2017). Penggunaan model PjBL untuk meningkatkan kreativitas mahasiswa dalam membuat media pembelajaran matematika. KALAMATIKA Jurnal Pendidikan Matematika, 2(2), 207-220.

Luthfi, R. M., Ismail, I., \& Wiharto, M. (2013). Memberdayakan keterampilan berpikir kreatif dan self regulated learning peserta didik melalui model project based learning. In Prosiding Seminar Nasional Biologi dan Pembelajarannya (pp. 123-128).

Iin Hindun, Husamah Implementasi Stad-Pjbl Untuk Meningkatkan Kreativitas Produk Mahasiswa Calon Guru Biologi 
Masruroh, A., Ibrohim, I., \& Masjhudi, M. (2016). Pengaruh model STAD (Student team achievement and division) dan PjBL (Project based learning) terhadap penguasaan konsep, kemampuan memecahkan masalah dan berpikir kreatif siswa SMA Negeri 1 Tumpang. Malang: Universitas Negeri Malang.

Maula, M. M., Prihatin, J., \& Fikri, K. (2014). Pengaruh model PjBL (Project-based learning) terhadap kemampuan berpikir kreatif dan hasil belajar siswa pada materi pengelolaan lingkungan. Artikel Ilmiah Mahasiswa, 1(1), 1-5.

Munawaroh, F. (2014). Pembelajaran berbasis proyek pada mata kuliah instrumentasi laboratorium untuk meningkatkan kreativitas dalam pembuatan alat peragaipa yang inovatif. Jurnal Pena Sains, 1(1), 60-66.

Muspiroh, N. (2015). Penerapan project base learning (PBP) bagi mahasiswa calon guru biologi pada mata kuliah sains terapan. Scientiae Educatia, 5(1), 1-8. doi: https://doi.org/10.24235/sc.educatia.v4i1.485

Nair, S. M., \& Kim, C. P. (2014). The effects of using the STAD method in teaching the short story, flipping fantastic on form one Students. In 2014th International Conference onEducation, Research and Innovation (Vol. 81, pp. 156-160). doi: https://doi.org/10.7763/IPEDR.2014.V81.24

Purwanti, S., \& Gafur, A. (2018). Penerapan pembelajaran kooperatif tipe STAD Untuk meningkatkan motivasi dan hasil belajar PKn. SOCIA Jurnal Ilmu-Ilmu Sosial, 15(2), 140-148.

Rais, M., \& Aryani, F. (2017). Pembelajaran reflektif: Seni berpikir kritis, analitis dan kreatif. Makassar: Badan Penerbit UNM.

Sari, R. T., \& Angreni, S. (2018). Penerapan model pembelajaran project based learning $(\mathrm{PjBL})$ upaya peningkatan kreativitas mahasiswa. Varia Pendidikan, 30(1), 79-83.

Sherman, L. W. (2001). Cooperative Learning and Computer-Supported Intentional Learning Experiences. Learning and Teaching on the World Wide Web, 113130. doi: https://doi.org/10.1016/b978-012761891-3/50009-6

Siswono, T. Y. E., Hartono, S., Kohar, A. W., Karim, K., \& Lastiningsih, N. (2019). How do prospective teachers manage students' learning of mathematics? TEM Journal, 8(2), 677-685. doi: https://doi.org/10.18421/TEM82-49

Smith, B. P. (2010). Instructional strategies in family and consumer sciences: 
Implementing the contextual teaching and learning pedagogical model. Journal of Family \& Consumer Sciences Education, 28(1), 23-38.

Susanti, S., Susilowibowo, J., \& Hardini, H. T. (2019). Effectiveness of Projectbased Learning Models to Improve Learning Outcomes and Learning Activities of Students in Innovative Learning. In K. S. Science (Ed.), 3rd ICEEBA International Conference on Economics, Education, Business and Accounting (Vol. 3, pp. 82-95). doi: https://doi.org/10.18502/kss.v3i11.4000

Suswanto, H., Hamdan, A., Mariana, R. R., Dardiri, A., Wibawa, A. P., Nafalski, A., \& Vianiryzki, A. F. (2017). The effectiveness of project-based learning and STAD learning on improving Web programming competency. World Transactions on Engineering and Technology Education, 15(4), 368-373.

Syam, A. N. (2016). Pengaruh model pembelajaran berbasis proyek (project based learning) terhadap hasil belajar biologi siswa di kelas VIII MTs Madani Alauddin Paopao. Fakultas Tarbiyah dan Keguruan UIN Alauddin Makassar.

Taylor, L., \& Parsons, J. (2011). Improving student engagement. Current Issues in Education, 14(1), 1-32. doi: https://doi.org/10.1007/s13398-014-0173-7.2

Tran, V. D. (2013). Effects of Student Teams Achievement Division (STAD) on academic achievement, and attitudes of grade 9th secondary school students towards mathematics. International Journal of Sciences, 2(4), 5-15. Retrieved from http://www.ijsciences.com

Trisdiono, H. (2014). Project Based- Learning in Teachers' Perspectives. DIJE, 2(5), 34-40.

Warawudhi, R. (2012). English reading achievement: Student Teams-Achievement Division (STAD) vs. Lecture Method for EFL learners. Journal of Institutional Research South East Asia, 10(1), 5-24.

Yuliarma, Y. (2010). Peningkatan kreativitas mahasiswa melalui pembelajaran training model dan penilaian portofolio. Jurnal Pendidikan Dan Kebudayaan, 16(1), 76-84. doi: https://doi.org/10.24832\%2Fjpnk.v16i1.433

Yustina, Y., \& Suwondo, S. (2015). Sikap ilmiah dan kreativitas produk pada isu lingkungan melalui pembelajaran berbasiskan proyek. BIOEDUKASI, 8(2), 48-52. doi: https://doi.org/10.20961/bioedukasi-uns.v8i2.3876

Zaturrahmi, Z., Hamdi, H., \& Ratnawulan, R. (2017). Penerapan model 
pembelajaran kooperatif tipe stad berbasis proyek membuat alat eksperimen sederhana untuk meningkatkan aktivitas belajar dan kompetensi fisika siswa di kelas XI TKR SMK Adzkia Padang. Gravity: Jurnal Ilmiah Penelitian Dan Pembelajaran Fisika, 3(2), 172-185. 